\title{
Nano-Structured Demineralized Human Dentin Matrix to Enhance Bone and Dental Repair and Regeneration
}

\author{
Xianling Gao ${ }^{1,2}$, Wei Qin ${ }^{1,2}$, Ping Wang ${ }^{2}$, Lin Wang ${ }^{2,3}$, Michael D. Weir ${ }^{2}$, Mark A. Reynolds ${ }^{2}$, \\ Liang Zhao ${ }^{2,4, *}$, Zhengmei Lin ${ }^{1, *}$ and Hockin $\mathrm{H}$. K. Xu ${ }^{2,5,6}$ \\ 1 Department of Operative Dentistry and Endodontics, Guanghua School of and hospital Stomatology \& \\ Guangdong Provincial Key Laboratory of Stomatology, Sun Yat-Sen University, Guangzhou 510055, China; \\ gaoxianl@mail2.sysu.edu.cn (X.G.); qinwei2@mail.sysu.edu.cn (W.Q.) \\ 2 Department of Advanced Oral Sciences and Therapeutics, University of Maryland, School of Dentistry, \\ Baltimore, MD 21201, USA; pingwangdental@temple.edu (P.W.); Wanglin1982@jlu.edu.cn (L.W.); \\ michael.weir@umaryland.edu (M.D.W.); MReynolds@umaryland.edu (M.A.R.); \\ hxu@umaryland.edu (H.H.K.X.) \\ 3 Department of Oral Implantology, School of Dentistry, Jilin University, Changchun 130021, China \\ 4 Department of Orthopedic Surgery, Nanfang Hospital, Southern Medical University, \\ Guangzhou 510515, China \\ 5 Center for Stem Cell Biology and Regenerative Medicine, University of Maryland School of Medicine, \\ Baltimore, MD 21201, USA \\ 6 University of Maryland Marlene and Stewart Greenebaum Cancer Center, University of Maryland School of \\ Medicine, Baltimore, MD 21201, USA \\ * Correspondence: lzhaonf@126.com (L.Z.); linzhm@mail.sysu.edu.cn (Z.L.)
}

Received: 3 February 2019; Accepted: 1 March 2019; Published: 12 March 2019

\begin{abstract}
Demineralized dentin matrix (DDM), derived from human teeth, is an excellent scaffold material with exciting bioactive properties to enhance bone and dental tissue engineering efficacy. In this article, first the nano-structure and bioactive components of the dentin matrix were reviewed. Then the preparation methods of DDM and the resulting properties were discussed. Next, the efficacy of DDM as a bone substitute with in vitro and in vivo properties were analyzed. In addition, the applications of DDM in tooth regeneration with promising results were described, and the drawbacks and future research needs were also discussed. With the extraction of growth factors from DDM and the nano-structural properties of DDM, previous studies also broadened the use of DDM as a bioactive carrier for growth factor delivery. In addition, due to its excellent physical and biological properties, DDM was also investigated for incorporation into other biomaterials design and fabrication, yielding great enhancements in hard tissue regeneration efficacy.
\end{abstract}

Keywords: dentin matrix; nano-sized minerals; bone tissue engineering; dental regeneration; scaffold carrier; growth factors

\section{Introduction}

Over two million bone graft operations are performed worldwide every year, and this number is increasing dramatically due to an aging population [1]. Autogenous bone is the gold-standard for bone repair. However, autogenous bone is available in limited amounts, and is usually harvested from the iliac crest, which is accompanied by a second operation and associated surgical risks in the donor site [2]. Therefore, there is an urgent need for alternative strategies, such as tissue engineering. Tissue engineering involves the development of scaffolds to mimic the extracellular matrix to aid new bone formation [3]. The scaffold should be biocompatible, biodegradable and 
porous [2]. Various types of scaffolds have been developed, including artificial polymers, natural polymers, calcium phosphate-based ceramics, and self-assembling peptides [4]. However, they have limited osteoinduction and bioactivity [4]. The introduction of growth factors in the scaffolds increases the bioactivity; however, it is associated with protein diffusion and high cost drawbacks $[5,6]$. In addition, the cell-based scaffolds are associated with complex challenges such as cell survival and cell diffusion [7].

Calcium phosphate biomaterials have been used for bone and tooth repairs; however, none of these materials possesses bioactivity comparable to autogenous bone and teeth [1]. Therefore, there is an urgent need for better scaffold materials. This review focuses on demineralized dentin matrix (DDM), originating from extracted human teeth. Teeth and bone have similar histogenesis, both originating from the neural crest during embryonic development [8]. Dentin and bone also have similar components, both composing of an organic phase (90\% type I collagen) and an intrafibrillar mineral phase (mostly apatite crystallites) [9]. The ratios of organic/inorganic components in human dentin and bone are both at approximately 2:1 [8]. Dentin was reported to have a bone-inducing function in 1967, and DDM was found to have better regenerative properties than undemineralized dentin matrix (UDM). Since then, several other studies were published on the use of DDM in tissue engineering [10-23]. However, to date, a literature search has revealed no review article on the application of DDM for teeth and bone regenerations.

Therefore, the objective of this article was to review the recent findings and cutting-edge research on the effects of DDM in promoting hard tissue repair and regeneration. First, we discussed the 3D hierarchical structures and components of DDM. Then, we described the preparation of DDM via various methods. Next, we summarized the investigations and major results in using DDM for bone and tooth regeneration. Finally, we offered insights into the application of DDM in the biomaterials development field, including the key challenges and potential solutions.

\section{Demineralized Dentin Matrix (DDM) Microstructure}

Dentin consists of about 65\% (by weight) inorganic substances, mainly hydroxyapatite (HA), tricalcium phosphate (TCP), octacalcium phosphate, amorphous calcium phosphate and dicalcium phosphate dehydrate [8]. The minerals consist of intrafibrillar mineral which is secreted by odontoblasts in a well-orchestrated order. Dentin contains about $35 \%$ (by weight) organic matrix and water [24]. The organic matrix includes collagen and non-collagenous components. The diameter of dentin collagen is approximately $80-100 \mathrm{~nm}$ [25]. Dentin collagen fibrils contain laterally organized microfibrillar units [26,27], which may be self-organized in a twisted arrangement of bundles, each measuring about $20 \mathrm{~nm}$ in diameter [28]. The next grade of structure in dentin collagen relates to each individual collagen microfibril, with $5-6 \mathrm{~nm}$ in diameter. Laterally, individual microfibrils contain five stranded triple-helical collagen molecules [26]. Besides minerals, collagen and water, dentin also contains about $5 \%$ non-collagenous components. The non-collagenous proteins, proteoglycans and enzymes play an important role in the development of dentin [29]. The small integrin-binding ligand N-linked glycoprotein (SIBLING) family includes osteopontin (OPN), bone sialoprotein (BSP), dentin matrix protein 1 (DMP1), dentin sialophosphoprotein (DSPP) and matrix extracellular phosphoglycoprotein (MEPE) [30]. The SIBLING family has key non-collagenous components, and they participate in the process of mineralization in dentin development [30].

The components of DDM are similar to those of the dentin matrix; however, they have different organic/inorganic ratios. DDM in powder form has a mineral content of about $5 \%-10 \%$, while DDM in block form has a mineral content of about $10 \%-30 \%$ [31]. The demineralization agents and time used to make DDM are different in different reports, and they affect the demineralization extent and mineral percentage in the resulting DDM. 
Growth factors are present in DDM, while they are trapped and hidden in UDM. The demineralization process opens the dentin tubules and frees up the growth factors, which can stimulate tissue repair and regeneration. Previous studies demonstrated transforming growth factor $\beta$ (TGF- $\beta 1$ ), bone morphogenetic proteins (BMPs), vascular endothelial growth factor (VEGF), fibroblast growth factor-2 (FGF-2), platelet-derived growth factor (PDGF) and insulin-like growth factor-1 (IGF-1) in DDM [32-36]. The amount of growth factors was detected by enzyme-linked immunosorbent assay (ELISA). Results showed that TGF- $\beta 1$ was the most abundant growth factor; BMP-2, FGF-2, VEGF, PDGF and IGF-1 demonstrated intermediate abundance; while BMP-4 and BMP-7 had the lowest concentrations, as shown in Table 1 [32]. DDM proposed osteogenic and dentingenic differentiation of bone mesenchymal stem cells (BMSCs), however, after fractionation of growth factors from DDM by heparin affinity chromatography, the osteogenic responses of BMSCs diminished, indicated that growth factors play significant role in the osteogenesis and dentingenesis of DDM. The growth factors are present at pg levels, have no toxicity issues and no potential for ectopic mineral deposit. These results demonstrated that DDM could deliver growth factors at physiological levels for bone regeneration [32].

Table 1. Quantification of growth factors in demineralized dentin matrix (DDM) detected by enzyme-linked immunosorbent assay (ELISA).

\begin{tabular}{ccccccccc}
\hline Growth Factor & TGF- $\beta 1$ & VEGF & BMP-2 & IGF-1 & FGF & PDGF & BMP-4 & BMP-7 \\
\hline ng/mg DDM & $15.6 \pm 7.9$ & $5.0 \pm 2.4$ & $6.2 \pm 1.7$ & $2.4 \pm 1.3$ & $5.5 \pm 1.0$ & $4.7 \pm 1.5$ & $0.12 \pm 0.07$ & $0.72 \pm 0.03$ \\
\hline
\end{tabular}

From Avery [32] in Eur Cell Mater, with permission.

Dentin contains micrometer-sized tubules [37]. The mineral surrounding the dentin tubules is highly mineralized and collagen-free, and is called peritubular dentin (PTD) (Figure 1A, black arrow). The mineral in the intertubular matrix is embedded in collagen-rich matrix (Figure 1A, white arrow), which is termed intertubular dentin (ITD) [37]. In making the DDM, the demineralization process mainly dissolves the mineral in PTD, producing opened and wider tubules and a meshwork protruding towards the tubule lumen (Figure 1B) [37]. Higher magnification images of demineralized dentin (Figure 1C) reveal a complex network of filaments protruding from tubule walls [37].
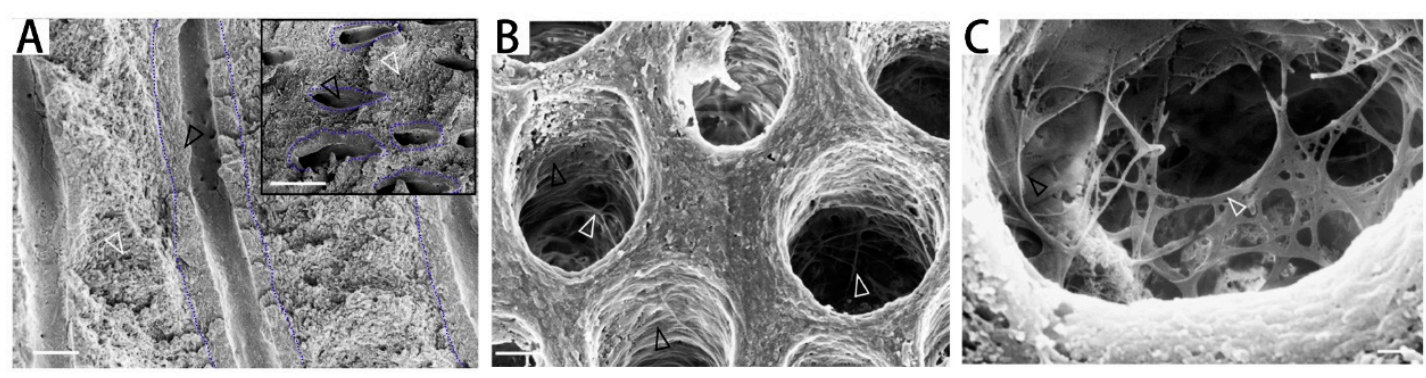

Figure 1. The nano-structure of dentin and DDM in scanning electron microscopy. (A) Dentin had micrometer-sized tubules. PTD was highly mineralized and collagen-free (black arrow). The mineral in ITD was embedded in collagen-rich matrix (white arrow). Scale bar $=1 \mu \mathrm{m}$ (larger figure). Scale bar $=2 \mu \mathrm{m}$ (inset). (B). Demineralization mainly dissolved the mineral in PTD, with opened and wider tubules, and a meshwork protruding towards the tubule lumen. Scale bar $=2 \mu \mathrm{m}$. (C) Higher magnification of demineralized dentin showing a complex network of filaments protruding from tubule walls. Scale bar $=2 \mu \mathrm{m}$. (From Berttasoni [37] in Micron, with permission.) 


\section{DDM Preparation}

To prepare DDM, clinically extracted teeth were collected, and all the soft tissues and enamel were removed. Dentin was grinded into particles, cut into slices or blocks, or perforated to get macropores. The resulting dentin particles or blocks were demineralized. Hydrochloric acid $(\mathrm{HCl})$ was most commonly used in demineralization. The demineralizing time ranged from $30 \mathrm{~min}$ to $24 \mathrm{~h} \mathrm{[38-40].} \mathrm{HNO}_{3}$ was also used in demineralization [17,41,42]. Dentin matrix was demineralized by $0.34 \mathrm{~N} \mathrm{HNO}_{3}$ for 30 mins, and the $\mathrm{HNO}_{3}$-DDM was grafted into critical-sized defect in the iliac crest of sheep. New bone formation was observed around DDM, and more bone volume was detected after 4 months than that at 2 months [41]. In another study, dentin matrix was treated with $2 \% \mathrm{HNO}_{3}$ for $10 \mathrm{~min}$, then transplanted into the tooth extraction pocket, and bone augmentation was observed [42]. Ethylene diamine tetra acetic acid (EDTA) was also used in demineralization $[16,32,43,44]$. The EDTA-demineralized dentin matrix is named treated dentin matrix (TDM) in some reports [32,44]. Gradient EDTA (17\%, 5\%) was employed to demineralize dentin matrix, and dentin tubules were exposed [43]. The EDTA concentration and demineralization time were also varied in different reports $[16,32,43,44]$.

Besides the demineralized agent, the size of the particles is also related to the effect of demineralization. A previous study divided dentin particles into three groups: 200, 500, and $1000 \mu \mathrm{m}$ [17]. To get 70\% demineralization of the dentin matrix (partially demineralized dentin matrix, PDDM), the 200, 500, $1000 \mu \mathrm{m}$, respectively, took 5, 10, and 20 min of treatments [17]. The terms DDM and PDDM are interchangeable in almost all the reports, because DDM is always partially demineralized. The bone regeneration effect of dentin matrix was evaluated via implantation into the rat calvaria bone defects. The results showed that the completely demineralized dentin matrix (CDDM) was largely resorbed, the UDM was remained, and both the CDDM and UDM induced little bone formation (Figure 2A). In sharp contrast, PDDM induced much more new bone than other groups (Figure 2A). In addition, the newly-formed bone (n-Bone\%) was quantitatively evaluated (Figure 2B). At 4 weeks, there was a significant difference of n-Bone \% between the PDDM and the other groups in each particle size. At 8 weeks, there was a significant difference of the n-Bone \% between the PDDM and the other groups in the 200 and $500 \mu \mathrm{m}$ particle size groups [17]. Few osteoblasts attached to the surface of UDM, while many osteoblasts attached and spread on the surface of DDM. In addition, UDM had limited growth factor exposure, while PDDM released several bioactive proteins. The demineralization opened the dentin tubules which served as channels for the release of these bioactive proteins when implanted in bone defects. Although CDDM also had opened tubules, the bioactive proteins may have already been released from dentin matrix during the process of demineralization, and therefore were lost before implantation. It was possible that PDDM contained more growth factors than CDDM. Furthermore, the $\mathrm{n}$-Bone $\%$ of the $1000 \mu \mathrm{m}$ group showed more bone regeneration than the smaller sizes; this was true in all groups of UDD, PDDM and CDDM (Figure 3B). Smaller particles had more resorbability, and they may have been resorbed in vivo before the initiation of new bone formation. Regarding the optimal particle size of DDM, there was no agreement in the literature, which varied in defect sites and graft materials, warranting further and more systematic investigations $[17,42,45]$.

Besides DDM particles, DDM blocks were also investigated $[14,18,23,41,46]$. In one study, DDM blocks with macropores were implanted into critical-sized iliac defects and new bone formation around the DDM had good union with the native bone [41]. Another study evaluated the characteristics of dentin blocks with different demineralization time (demineralized for $10 \mathrm{~min}$, DDB10; for $60 \mathrm{~min}$, DDB60), and assessed new bone formation after grafting the dentin blocks in rat calvaria defects. The DDB60 group resulted in significantly more new bone area than the DDB10 group at 8 weeks, but had higher resorption which reduced the total augmented area when compared with DDB10 [47]. The relationship between the demineralized degree and the new bone induction using DDM blocks was consistent with that using DDM particles [17]. 
A

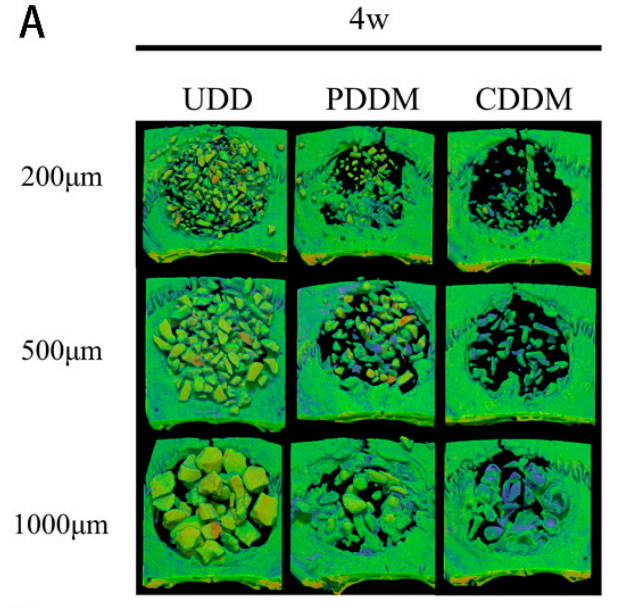

B

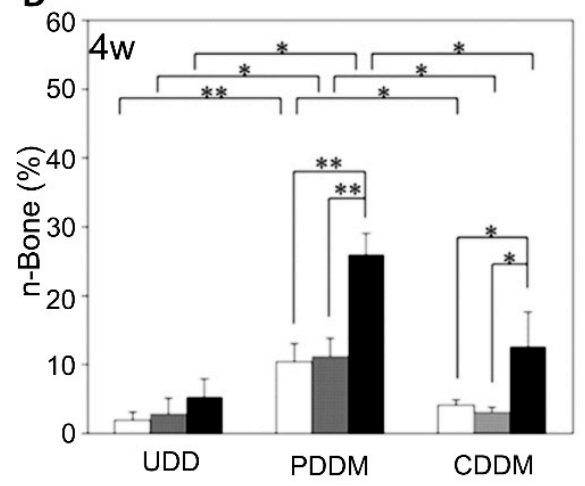

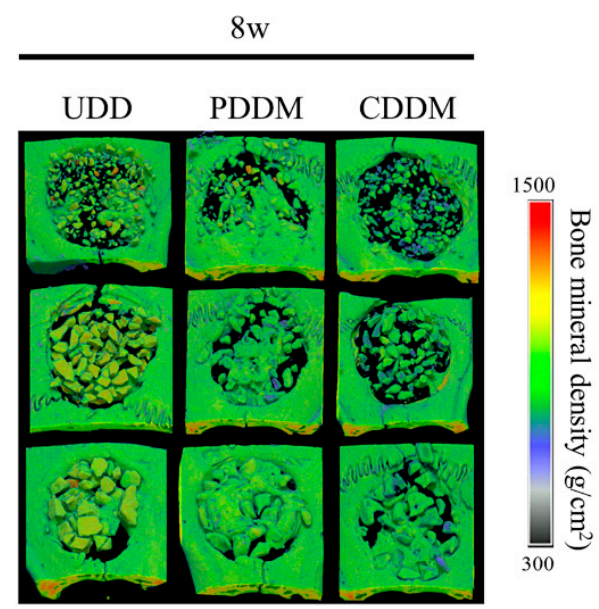

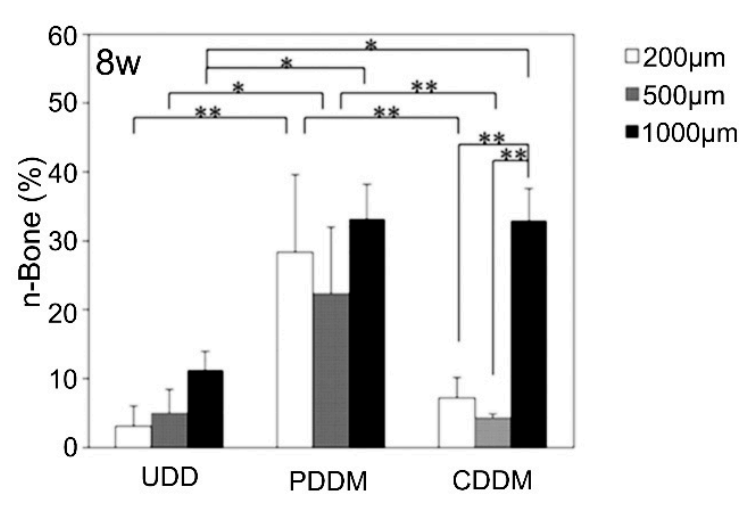

Figure 2. The dentin matrix-induced bone formation depended on the degree of demineralization and particle size. (A) Micro-CT analysis. New bone formation was enhanced in all particle sizes in PDDM groups, more than in CDDM groups. The results of $1000 \mu \mathrm{m}$ PDDM were especially noteworthy. In contrast, in UDD groups, much less new bone formed, and defects were occupied by dentin particles. (B) Newly formed bone (n-Bone\%) were quantitatively evaluated. At 4 weeks, there is significant difference of n-Bone\% between the PDDM and other groups in each particle size. At 8 weeks, there is a significant difference of the n-Bone\% between the PDDM and the other groups in the 200 and $500 \mu \mathrm{m}$ samples. (From Takamitsu [17] in PLOS ONE, with permission.)

\section{Application of DDM in Bone Regeneration}

Extensive studies have been conducted on DDM with its osteoinductivity and osteoconductivity in vitro and in vivo $[17,18,48-51]$. In animal studies, DDM enhanced the bone healing process of tooth sockets, and promoted new bone formation in rat calvaria defects, rabbit parietal defects, minipig crania defects, sheep iliac defects, and porcine sinus [17,18,41,47-49,52]. Besides bone, DDM was employed in osteochondral regeneration [20]. DDM was implanted in rabbit keens with articular cartilage defects, while the control group was left untreated. Samples were collected in pre-determined timepoints and examined histologically and radiographically. The DDM group had statistically more new bone formation inside the defect, compared with control group at week three. Hyaline-like cartilage appeared in the peripheral area of the defect at week six, while the control group had none. The sample surface was covered with hyaline-like cartilage with a similar thickness to that of normal cartilage at week nine. Besides animal experiments, clinical trials were also launched. The Korea Tooth Bank and Hospital Tooth Bank (HTB) established a system to store teeth, then process them into DDM as bone substitutes [8]. One clinical study examined the safety and efficacy of autogenous DDM prepared immediately after extraction, for clinical applications in bone regeneration related to dental implantation, including: (1) socket preservation, (2) maxillary sinus floor augmentation, and (3) alveolar ridge augmentation. Sixteen patients underwent dental implant placement using 
DDM transplantation. The results showed that: (1) in the socket preservation group, the height and width of the alveolar ridge were clinically preserved in all cases. (2) In the maxillary sinus floor augmentation group, the vertical height from the top of the alveolar crest to the sinus floor was increased after autogenous implantation, from $3.4 \mathrm{~mm}$ to $9.5 \mathrm{~mm}$ before surgery to $14.7 \mathrm{~mm}$ to $17.1 \mathrm{~mm}$ 3 months post-operation. The height of the augmentation area maintained for at least 1 year. (3) In the alveolar ridge augmentation group with implant placement, the autogenous DDM was replaced by bone-like tissue 3 months after dental implant placement. In all three groups, the graft sites healed without any notable complications. No implants were lost over 2 years of observation. This report showed that the clinical application of autogenous DDM was safe and efficient as a bone substitute in implant dentistry [42]. Another clinical study compared the efficacy of autogenous DDM and Bio-Oss (inorganic bovine bone) in alveolar bone augmentation and found that the autogenous DDM was as effective as Bio-Oss [53]. A long-term follow up of guided bone regeneration using DDM reported five cases which were followed for 3 to 6 months after DDM grafting. The results showed that the corticocancellous bone which formed after implantation was maintained for an average of 5 years [12]. The results of these clinical researches on DDM were consistent and promising. However, the number of cases was relatively small, and more randomized control trial clinical studies are needed.

\section{Application of DDM in Tooth Regeneration}

Besides bone regeneration, DDM has also been investigated for tooth regeneration applications [10,54-56]. The bioactive molecules in the dentin matrix participate in naturally regenerative dentin formation in cases of trauma and infection. Indeed, the bioactive molecules from DDM can influence the survival, apoptosis and differentiation of human dental pulp stem cells (hDPSCs) [54]. DDM extracts were found to promote hDPSC expansion, decrease apoptotic markers expression, stimulate cell survival markers expression, and promote mineral synthesis and osteogenic related genes expression [54]. DDM was also effective in inducing odontogenic differentiation in hDPSCs. The odontogenically-related genes includingDMP1 and DSPP were found to be upregulated [55]. Another study compared the osteogenic induction and odontogenic induction of DDM with HA/TCP on hDPSCs, and found that DDM and HA/TCP had similar efficiencies in bone formation in the dorsum of immunodeficiency mice, while DDM induced greater dentinogenic differentiation [57]. Therefore, DDM had biological effects on DPSCs and could orchestrate dental tissue repairs.

In addition, Ferracane et al. studied the dentin matrix using another approach [50]. Different $\mathrm{pH}$ of phosphoric acid and EDTA were employed to solubilize bioactive molecules from the powdered dentin matrix. They collected the demineralized solution and named it dentin matrix components (DMC). Two different pulp cell populations were treated with different concentrations of DMC $(0.01,0.1,1.0$ and $10.0 \mu \mathrm{g} / \mathrm{mL})$. Their results showed that DMC could promote cell proliferation and mineralization, and the $10 \mu \mathrm{g} / \mathrm{mL}$ concentration had the greatest mineralization among all the tested groups [50].

Chen et al. developed a novel pulp capping agent using TDM [10]. The TDM powder and aqueous TDM extract were prepared, and then they were mixed to form the TDM paste as the pulp capping agent. Calcium hydroxide was used as control. The TDM paste showed more odontogenic gene expression in vitro than calcium hydroxide. In the pulp exposure model in swine, TDM showed better biocompatibility, thicker and more dense dentin bridge formation, and less angiectasis in the pulp under the dentin bridge, compared to calcium hydroxide (Figure 3) [10]. These results showed that the TDM paste could be a promising pulp capping agent. Another study used cryopreserved dentin matrix $(\mathrm{CDM})$ as a scaffold material for dentin-pulp tissue regeneration. CDM was implanted into the dorsum of immunodeficient mice. The results showed that CDM combined with dental follicle cells could form dentin-pulp like tissues which were positive for DSPP, DMP-1, tubulin, and collagen-1. The dentin-pulp-like tissues included pre-dentin, dentinal tubules, collagen fibers, blood vessels and nerves [58]. In another study, DDM was combined with dental follicle cells and implanted in a mouse model for 8 weeks, where the TDM induced complete dentin tissues [16]. Therefore, 
TDM was an excellent biomaterial for dentin regeneration. Inspired by the fact that the EDTA-treated dentin matrix could release considerable bioactive molecules, the notion of DDM was introduced into revascularization treatments [59]. Two young patients with necrotic immature permanent teeth were chosen for the revascularization treatment. After appropriate disinfection of the root canal system, different concentrations of EDTA were used to treat root canal dentin walls. Then, bleeding was induced in root canals, and calcium-enriched mixture cement was placed over the blood clots. In all follow-up periods (6 and 12 months), both cases were asymptomatic, and the radiographic findings showed a continued root development [59]. The modification in revascularization through the DDM protocol appeared to be better than the traditional therapy. Therefore, the effect of DDM in tooth regeneration is promising and is a hotspot research area; however, more systematic experiments are needed to validate the efficacy and safety of DDM in tooth regeneration applications.

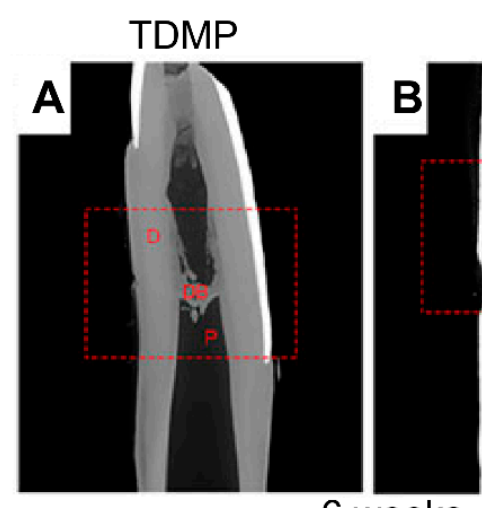

6 weeks
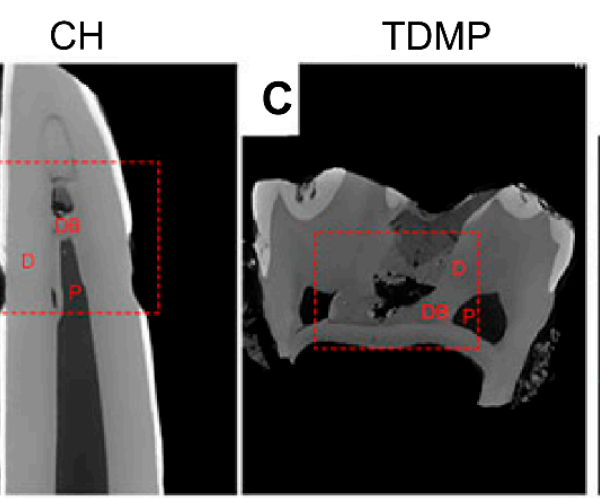

10 weeks

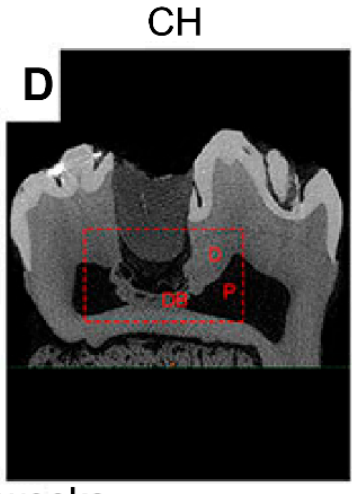

Figure 3. In vivo pulp-capping effects after pulp exposure. Dentin bridge formation was analyzed by Micro-CT. (From Chen [10] J. Tissue Eng. Regen. Med., with permission.)

\section{DDM as a Carrier to Deliver Growth Factors}

Besides serving as a scaffold to support bone regeneration and as a nature reservoir of growth factors, DDM can also serve as a delivery vehicle for additional growth factors. The tubules in DDM provide a high specific surface area and are advantageous to increase the protein retain and reduce protein diffusional loss [60]. Indeed, DDM has been employed as a recombinant human BMP-2 (rhBMP-2) carrier involving in vitro, in vivo and clinical trials [61-65] In one study, the dentin matrix was demineralized, then DDM was mixed with BMP-2 solutions, and the BMP-2/DDM composite was grafted into the skin over the back region of immunodeficiency mice [62]. The results showed that the volume of induced bone increased at a BMP-2 dose-dependent manner. The time-dependent study of bone induction by the BMP-2 $(5.0 \mu \mathrm{g})$ with DDM $(70 \mathrm{mg})$ showed that the BMP-2 and DDM construct increased new bone formation between the DDM particles. The dry weight of the repair tissue, the ALP activity and calcium content in the BMP-2/DDM group were higher when compared with the DDM alone group (Figure 4) [62]. In another study, 5.0 ug of $0.2 \mathrm{mg} / \mathrm{mL} \mathrm{rhBMP}-2$ was placed onto $0.03 \mathrm{~g}$ of DDM, then the mixture was lyophilized and sterilized [63]. The DDM/rhMP-2 construct was transplanted into rectangular bone defects on the second and third premolars in beagles. DDM with rhBMP-2 showed $48 \%$ new bone formation 12 weeks after transplantation. Clinical studies were also launched in patients. The DDM/rhBMP-2 complex was grafted into patients, with surgeries including guided bone regeneration, sinus bone grafting, and ridge augmentation. At an average follow up of 10.5 months, favorable osseointegration was acquired in 35 out of 36 implanted sites [63]. In another case report, the DDM/rhBMP-2 construct was used for socket preservation, and the new bone amount was more in DDM/rhBMP-2 group than in DDM group [64]. In a prospective randomized controlled trial of DDM/rhBMP-2 in ridge preservation, DDM, DDM/rhBMP-2, and deproteinized bovine bone with collagen (DBBC), a conventional xenograft, were transplanted into the extraction pockets immediately after tooth extraction [66]. DDM was as beneficial for ridge preservation as DBBC. 
The DDM/rhBMP-2 showed appreciable volumetric stability and higher rates new bone formation compared to DDM alone and DBBC [66]. Compared to conventional BMP-2 carriers, the advantage of DDM as the carrier was that DDM was osteoconductive and osteoinductive, and could synergistically combine the properties of the scaffold with the delivered growth factors. However, further studies are needed to investigate the rhBMP-2 concentration and amount, the DDM particle size, the processing method of DDM, the loading method of rhBMP-2 into DDM, and the synergistic effects of rhBMP-2 with the DDM growth factors on tissue regeneration. In addition, besides BMP-2, the delivery of other growth factors via DDM to promote bone and dental tissue regeneration also needs to be investigated.

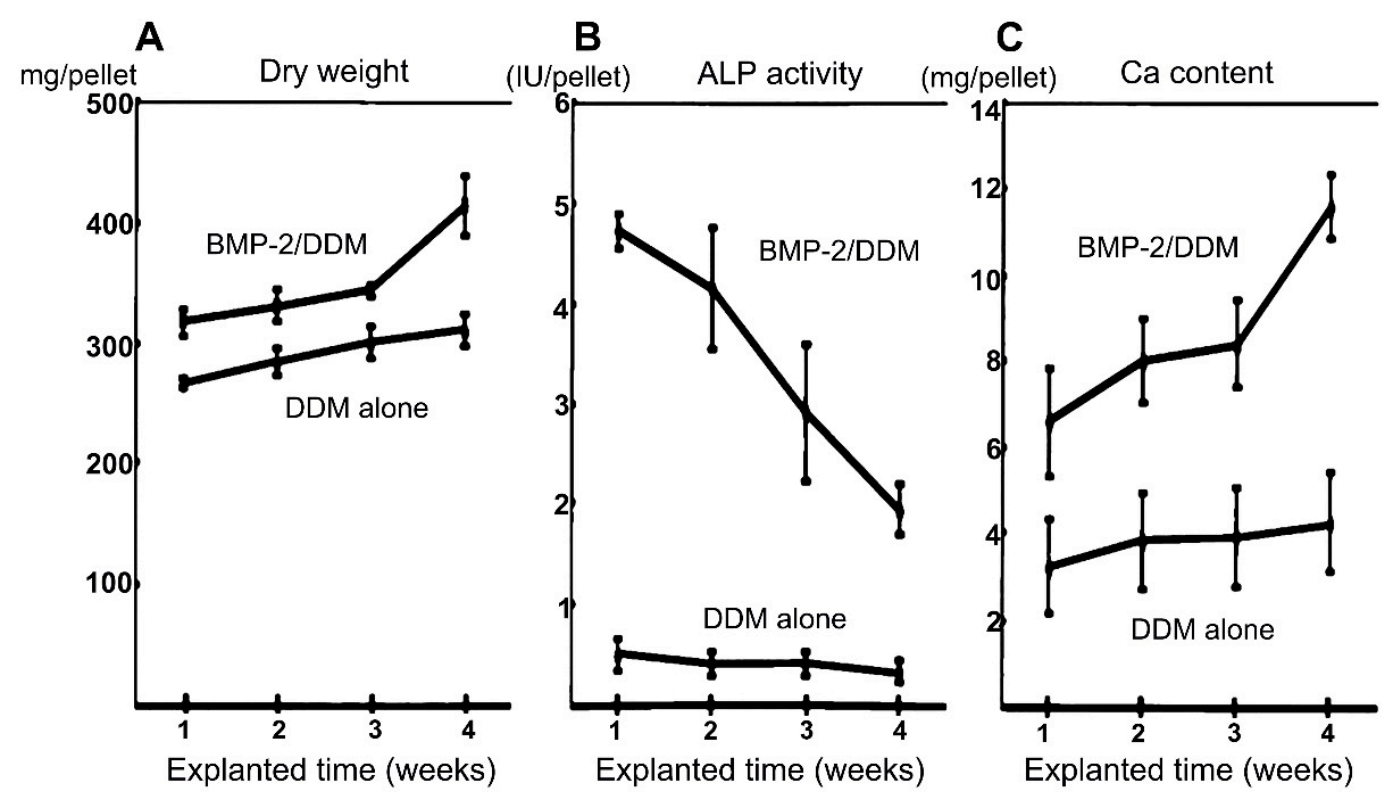

Figure 4. Biochemical changes after implantation in DDM/rhBMP-2 group and DDM group. (A) Dry weight (mg/pellet). (B) ALP activity (IU/pellet). (C) Ca content (mg/pellet). (From Murata [62] Journal of Biomedical Baterials Research Part A, with permission.)

\section{DDM Incorporation into Other Advanced Biomaterials}

DDM alone showed promising effects in bone and tooth regeneration. In addition, the dentin matrix could also be incorporated into other biomaterials [40,43,67-69]. For example, TDM, aligned PLGA/Gelatin electrospun sheet (APES), and native dental pulp extracellular matrix (DPEM) were combined into DPEM/TDM construct and APES/TDM construct for dental pulp and periodontium regeneration. Both APES/TDM and DPEM/TDM prompted odontogenic differentiation of dental stem cells, while the groups without TDM did not (Figure 5). Then the combinations were implanted into tooth pockets in swine. After 12 weeks, new pulp/dentin complex-like tissues were formed on the DPEM/TDM surface, and cementum and periodontal ligament-like tissues were formed on the APES/TDM surface [69]. Therefore, the APES/TDM and DPEM/TDM complexes offered an inspiration for complex tissue or organ regeneration. In a 3D-bioprinting study, DDM was mixed with alginate hydrogels as a bioink, which was blended with cells and then bioprinted (Figure 6). The bioinks modified by the dentin matrix demonstrated good cytocompatibility and natural odontogenic capacity [70]. In another study, the TDM combined with Mg-based bioceramic scaffolds and dentinogenesis-related morphogens, were developed and applied to induce dentin-like tissue formation [67]. In another study, the root dentin matrix was demineralized by EDTA to obtain TDM roots, and then the TDM roots were combined with platelet rich fibrin (PRF). The combination of TDM/PRF were placed into the tooth extraction pockets in canines, which achieved functional regeneration of the cementum and the periodontal ligament fibers [68]. Therefore, the dentin matrix represents an important bioactive and nano-structured material that can be incorporated into the development of other advanced biomaterials to enhance tissue repair and regeneration. 

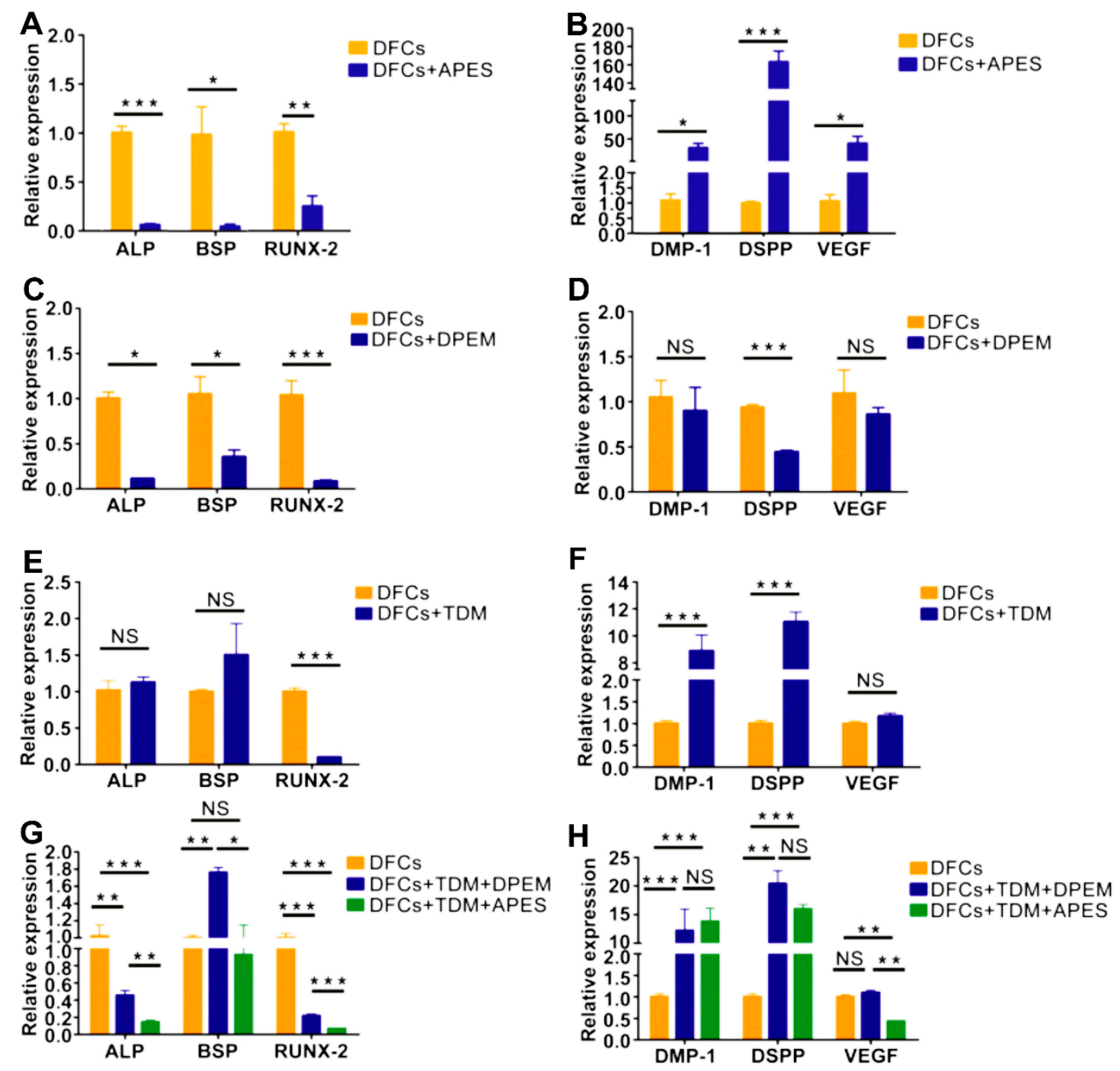

Figure 5. The combination of APES/TDM and DPEM/TDM on odontoblastic differentiation of DPSCs. (A,B) The APES group up-regulated DSPP and DMP-1, two classic odontogenic markers. Meanwhile, the expression of vasculogenesis and angiogenesis marker VEGF was up-regulated, but early osteogenic/odontogenic markers ALP, BSP and RUNX-2, were down-regulated. (C,D) In DPEM group, the expression of ALP, BSP and RUNX-2 expression were inhibited. The expression of DMP-1 and VEGF did not change. (E,F) In TDM group, DMP-1 and DSPP were up-regulated, but ALP, BSP and VEGF were not. $(\mathbf{G}, \mathbf{H})$ In the group of DPEM/TDM or APES/TDM, the expression of DMP-1 and DSPP were up-regulated, while ALP and RUNX-2 were down-regulated. Interestingly, DPEM/TDM not only up-regulated BSP, but also kept the expression level of VEGF. ${ }^{*} p<0.05,{ }^{* *} p<0.01,{ }^{* * *} p<0.001$, NS: no significance. (From Chen [69], Biomaterials, with permission.) 


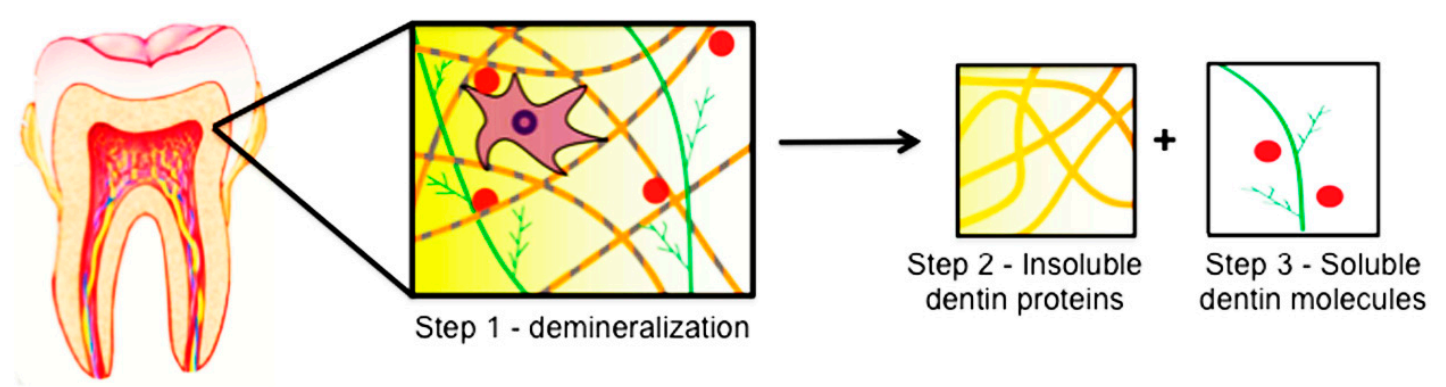

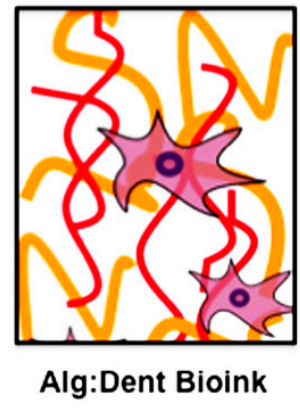

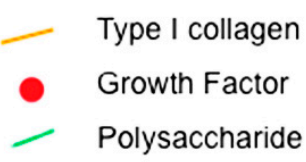

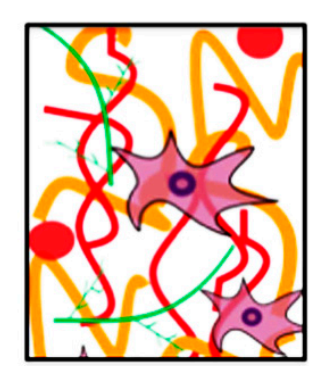

Alg:Dent Bioink + Soluble Dentin Molecules

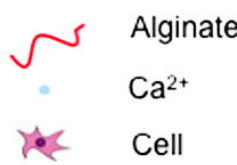

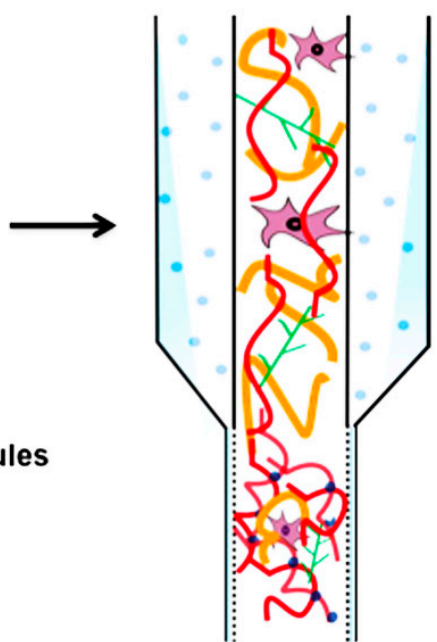

Step 4 - 3D Bioprinting with Cell-laden Bioink

Figure 6. Schematic description of the dentin bioink for 3D-bioprinting. The bioink was made of insoluble dentin proteins, soluble dentin molecules and alginate hydrogel. (From Athirasala [70] Biofabrication, with permission.)

\section{Conclusions}

This article represents the first comprehensive review on the application of DDM for bone and dental regeneration. (1) DDM demonstrated great potential for applications in bone regeneration; however, more randomized clinical studies are still needed. (2) The use of DDM in tooth regeneration was promising. Exciting results were obtained in dentin, pulp and periodontal regeneration via DDM. However, more experiments are needed to validate the efficacy and safety of DDM in tooth regeneration applications. (3) In addition, the use of DDM as a growth factor carrier was recognized to further enhance tissue regeneration efficacy. (4) Furthermore, the incorporation of DDM into other biomaterials was highly beneficial by utilizing the excellent properties of DDM with its inherent growth factors and nano-minerals to promote bone and dental regeneration.

Author Contributions: X.G., W.Q. and H.H.K.X. proposed the ideas and wrote the first draft. H.H.K.X., Z.L. and L.Z. reviewed and revised the paper. P.W., L.W., M.D.W. and M.A.R. revised the paper. All the authors contributed in discussions and read and approved the final version of the manuscript.

Funding: This study was supported by the University of Maryland Baltimore seed grant (H.X.); University of Maryland School of Dentistry bridge grant (H.X.); the National Science Foundation of China 81670984 (Z.L.), 81873713 (Z.L.) and 31771051(L.Z.); the International Cooperation Project of Science and Technology in Guangdong Province 2016B050502008 (Z.L.); Guangzhou Social Science Foundation of China 706054936110 (L.Z.); Guangdong Science Foundation 2018B030311041 (L.Z.).

Conflicts of Interest: The authors declare no conflict of interest. 


\section{References}

1. Pereira, D.D.M.; Habibovic, P. Biomineralization-Inspired Material Design for Bone Regeneration. Adv. Healthc. Mater. 2018, 7, 1800700. [CrossRef] [PubMed]

2. Dimitriou, R.; Mataliotakis, G.I.; Angoules, A.G.; Kanakaris, N.K.; Giannoudis, P.V. Complications Following Autologous Bone Graft Harvesting from the Iliac Crest and Using the Ria: A Systematic Review. Injury 2011, 42, S3-S15. [CrossRef] [PubMed]

3. Zhang, W.; Feng, C.; Yang, G.; Li, G.; Ding, X.; Wang, S.; Dou, Y.; Zhang, Z.; Chang, J.; Wu, C.; et al. 3d-Printed Scaffolds with Synergistic Effect of Hollow-Pipe Structure and Bioactive Ions for Vascularized Bone Regeneration. Biomaterials 2017, 135, 85-95. [CrossRef] [PubMed]

4. Winkler, T.; Sass, F.A.; Duda, G.N.; Schmidt-Bleek, K. A Review of Biomaterials in Bone Defect Healing, Remaining Shortcomings and Future Opportunities for Bone Tissue Engineering: The Unsolved Challenge. Bone Joint Res. 2018, 7, 232-243. [CrossRef] [PubMed]

5. Ritting, A.W.; Weber, E.W.; Lee, M.C. Exaggerated Inflammatory Response and Bony Resorption from Bmp-2 Use in a Pediatric Forearm Nonunion. J. Hand Surg. 2012, 37, 316-321. [CrossRef] [PubMed]

6. Kempen, D.H.R.; Lu, L.; Heijink, A.; Hefferan, T.E.; Creemers, L.B.; Maran, A.; Yaszemski, M.J.; Dhert, W.J.A. Effect of Local Sequential Vegf and Bmp-2 Delivery on Ectopic and Orthotopic Bone Regeneration. Biomaterials 2009, 30, 2816-2825. [CrossRef] [PubMed]

7. Moya, A.; Paquet, J.; Deschepper, M.; Larochette, N.; Oudina, K.; Denoeud, C.; Bensidhoum, M.; Logeart-Avramoglou, D.; Petite, H. Human Mesenchymal Stem Cell Failure to Adapt to Glucose Shortage and Rapidly Use Intracellular Energy Reserves through Glycolysis Explains Poor Cell Survival after Implantation. Stem Cells 2018, 36, 363-376. [CrossRef] [PubMed]

8. Kim, Y.K.; Lee, J.; Um, I.W.; Kim, K.W.; Murata, M.; Akazawa, T.; Mitsugi, M. Tooth-Derived Bone Graft Material. J. Korean Assoc. Oral Maxillofac. Surg. 2013, 39, 103. [CrossRef] [PubMed]

9. Kruzic, J.J.; Ritchie, R.O. Fatigue of Mineralized Tissues: Cortical Bone and Dentin. Mech. Behav. Biomed. 2008, 1, 3-17. [CrossRef] [PubMed]

10. Chen, J.; Cui, C.; Qiao, X.; Yang, B.; Yu, M.; Guo, W.; Tian, W. Treated Dentin Matrix Paste as a Novel Pulp Capping Agent for Dentin Regeneration. J. Tissue Eng. Regen. Med. 2017, 11, 3428-3436. [CrossRef] [PubMed]

11. Li, X.; Ma, C.; Xie, X.; Sun, H.; Liu, X. Pulp Regeneration in a Full-Length Human Tooth Root Using a Hierarchical Nanofibrous Microsphere System. Acta Biomater. 2016, 35, 57-67. [CrossRef] [PubMed]

12. Kim, Y.K.; Lee, J.H.; Um, I.W.; Cho, W.J. Guided Bone Regeneration Using Demineralized Dentin Matrix: Long-Term Follow-Up. J. Oral Maxil. Surg. 2016, 74, 515. [CrossRef] [PubMed]

13. Qin, X.; Zou, F.; Chen, W.; Xu, Y.; Ma, B.; Huang, Z.; Zhu, G.; Zhou, B. Demineralized Dentin as a Semi-Rigid Barrier for Guiding Periodontal Tissue Regeneration. J. Periodontol. 2015, 86, 1370-1379. [CrossRef] [PubMed]

14. Yang, B.; Chen, G.; Li, J.; Zou, Q.; Xie, D.; Chen, Y.; Wang, H.; Zheng, X.; Long, J.; Tang, W.; et al. Tooth Root Regeneration Using Dental Follicle Cell Sheets in Combination with a Dentin Matrix-Based Scaffold. Biomaterials 2012, 33, 2449-2461. [CrossRef] [PubMed]

15. Guo, W.; Gong, K.; Shi, H.; Zhu, G.; He, Y.; Ding, B.; Wen, L.; Jin, Y. Dental Follicle Cells and Treated Dentin Matrix Scaffold for Tissue Engineering the Tooth Root. Biomaterials 2012, 33, 1291-1302. [CrossRef] [PubMed]

16. Li, R.; Guo, W.; Yang, B.; Guo, L.; Sheng, L.; Chen, G.; Li, Y.; Zou, Q.; Xie, D.; An, X.; et al. Human Treated Dentin Matrix as a Natural Scaffold for Complete Human Dentin Tissue Regeneration. Biomaterials 2011, 32, 4525-4538. [CrossRef] [PubMed]

17. Koga, T.; Minamizato, T.; Kawai, Y.; Miura, K.I.; Takashi, I.; Nakatani, Y.; Sumita, Y.; Asahina, I. Bone Regeneration Using Dentin Matrix Depends on the Degree of Demineralization and Particle Size. PLoS ONE 2016, 11, e0147235. [CrossRef] [PubMed]

18. Togari, K.; Miyazawa, K.; Yagihashi, K.; Tabuchi, M.; Maeda, H.; Kawai, T.; Goto, S. Bone Regeneration by Demineralized Dentin Matrix in Skull Defects of Rats. J. Hard Tissue Biol. 2012, 21, 25-33. [CrossRef]

19. Reis-Filho, C.R.; Silva, E.R.; Martins, A.B.; Pessoa, F.F.; Gomes, P.V.; de Araújo, M.S.; Miziara, M.N.; Alves, J.B. Demineralised Human Dentine Matrix Stimulates the Expression of Vegf and Accelerates the Bone Repair in Tooth Sockets of Rats. Arch. Oral Biol. 2012, 57, 469. [CrossRef] [PubMed]

20. Yagihashi, K.; Miyazawa, K.; Togari, K.; Goto, S. Demineralized Dentin Matrix Acts as a Scaffold for Repair of Articular Cartilage Defects. Calcified Tissue Int. 2009, 84, 210-220. [CrossRef] [PubMed] 
21. Gomes, M.F.; dos Anjos, M.J.; Nogueira Tde, O.; Catanzaro Guimaraes, S.A. Autogenous Demineralized Dentin Matrix for Tissue Engineering Applications: Radiographic and Histomorphometric Studies. Int. J. Oral Max. Implants 2002, 17, 488-497.

22. Carvalho, V.A.; Tosello Dde, O.; Salgado, M.A.; Gomes, M.F. Histomorphometric Analysis of Homogenous Demineralized Den tin Matrix as Osteopromotive Material in Rabbit Mandibles. Int. J. Oral Maxillofac Implants 2004, 19, 679-686. [PubMed]

23. Bormann, K.H.; Suarez-Cunqueiro, M.M.; Sinikovic, B.; Kampmann, A.; See, C.V.; Tavassol, F.; Binger, T.; Winkler, M.; Gellrich, N.C.; Rücker, M. Dentin as a Suitable Bone Substitute Comparable to $\beta$-TCP-an Experimental Study in Mice. Microvasc. Res. 2012, 84, 116-122. [CrossRef] [PubMed]

24. Bertassoni, L.E. Dentin on the Nanoscale: Hierarchical Organization, Mechanical Behavior and Bioinspired Engineering. Dent. Mater. 2017, 33, 637-649. [CrossRef] [PubMed]

25. Habelitz, S.; Balooch, M.; Marshall, S.J.; Balooch, G.; Marshall, G.W., Jr. In Situ Atomic Force Microscopy of Partially Demineralized Human Dentin Collagen Fibrils. J. Struct. Biol. 2002, 138, 227-236. [CrossRef]

26. Orgel, J.P.; Irving, T.C.; Miller, A.; Wess, T.J. Microfibrillar Structure of Type I Collagen in Situ. Proc. Natl. Acad. Sci. USA 2006, 103, 9001-9005. [CrossRef] [PubMed]

27. Goh, K.; Hiller, J.; Haston, J.; Kadler, K.; Murdoch, A.; Meakin, J.; Wess, T. Analysis of Collagen Fibril Diameter Distribution in Connective Tissues Using Small-Angle X-Ray Scattering. BBA Gen. Subj. 2005, 1722, 183-188. [CrossRef] [PubMed]

28. Bertassoni, L.E.; Swain, M.V. Removal of Dentin Non-Collagenous Structures Results in the Unraveling of Microfibril Bundles in Collagen Type I. Connect. Tissue Res. 2017, 58, 1-10. [CrossRef] [PubMed]

29. Butler, W.T.; Brunn, J.C.; Qin, C. Dentin Extracellular Matrix (Ecm) Proteins: Comparison to Bone Ecm and Contribution to Dynamics of Dentinogenesis. Connect. Tissue Res. 2003, 44, 171-178. [CrossRef] [PubMed]

30. Katherine, A.S.; Vicky, E.M.; Colin, F. The Importance of the Sibling Family of Proteins on Skeletal Mineralisation and Bone Remodelling. J. Endocrinol. 2012, 214, 241.

31. Um, I.W.; Kim, Y.K.; Mitsugi, M. Demineralized Dentin Matrix Scaffolds for Alveolar Bone Engineering. J. Indian Prosthodont. Soc. 2017, 17, 120. [CrossRef] [PubMed]

32. Avery, S.J.; Sadaghiani, L.; Sloan, A.J.; Waddington, R.J. Analysing the Bioactive Makeup of Demineralised Dentine Matrix on Bone Marrow Mesenchymal Stem Cells for Enhanced Bone Repair. Eur. Cell Mater. 2017, 34, 1-14. [CrossRef] [PubMed]

33. Ranc, V.; Zizka, R.; Chaloupkova, Z.; Sevcik, J.; Zboril, R. Imaging of Growth Factors on a Human Tooth Root Canal by Surface-Enhanced Raman Spectroscopy. Anal. Bioanal. Chem. 2018, 410, 7113-7120. [CrossRef] [PubMed]

34. Schmidt-Schultz, T.; Schultz, M. Intact Growth Factors Are Conserved in the Extracellular Matrix of Ancient Human Bone and Teeth: A Storehouse for the Study of Human Evolution in Health and Disease. Biol. Chem. 2005, 386, 767. [CrossRef] [PubMed]

35. Baker, S.M.; Sugars, R.V.; Wendel, M.; Smith, A.J.; Waddington, R.J.; Cooper, P.R.; Sloan, A.J. Tgf-B/Extracellular Matrix Interactions in Dentin Matrix: A Role in Regulating Sequestration and Protection of Bioactivity. Calcified Tissue Int. 2009, 85, 66-74. [CrossRef] [PubMed]

36. Zhang, R.; Cooper, P.R.; Smith, G.; Nor, J.E.; Smith, A.J. Angiogenic Activity of Dentin Matrix Components. J. Endodon. 2011, 37, 26-30. [CrossRef] [PubMed]

37. Bertassoni, L.E.; Stankoska, K.; Swain, M.V. Insights into the Structure and Composition of the Peritubular Dentin Organic Matrix and the Lamina Limitans. Micron 2012, 43, 229-236. [CrossRef] [PubMed]

38. Huang, B.; Sun, Y.; Maciejewska, I.; Qin, D.; Peng, T.; McIntyre, B.; Wygant, J.; Butler, W.T.; Qin, C. Distribution of Sibling Proteins in the Organic and Inorganic Phases of Rat Dentin and Bone. Eur. J. Oral Sci. 2008, 116, 104-112.

39. Um, I.W.; Jun, S.H.; Yun, P.Y.; Kim, Y.K. Histological Comparison of Autogenous and Allogenic Demineralized Dentin Matrix Loaded with Recombinant Human Bone Morphogenetic Protein-2 for Alveolar Bone Repair: A Preliminary Report. J. Hard Tissue Biol. 2017, 26, 417-423. [CrossRef]

40. Li, J.; Yang, J.; Zhong, X.; He, F.; Wu, X.; Shen, G. Demineralized Dentin Matrix Composite Collagen Material for Bone Tissue Regeneration. J. Biomater. Sci. Polym. Ed. 2013, 24, 1519-1528. [CrossRef] [PubMed]

41. Kabir, M.A.; Murata, M.; Akazawa, T.; Kusano, K.; Yamada, K.; Ito, M. Evaluation of Perforated Demineralized Dentin Scaffold on Bone Regeneration in Critical-Size Sheep Iliac Defects. Clin. Oral Implants Res. 2017, 28, e227-e235. [CrossRef] [PubMed] 
42. Minamizato, T.; Koga, T.; Takashi, I.; Nakatani, Y.; Umebayashi, M.; Sumita, Y.; Ikeda, T.; Asahina, I. Clinical Application of Autogenous Partially Demineralized Dentin Matrix Prepared Immediately after Extraction for Alveolar Bone Regeneration in Implant Dentistry: A Pilot Study. Int. J. Oral Maxillofac. Surg. 2018, 47, 125-132. [CrossRef] [PubMed]

43. Guo, W.; He, Y.; Zhang, X.; Lu, W.; Wang, C.; Yu, H.; Liu, Y.; Li, Y.; Zhou, Y.; Zhou, J.; et al. The Use of Dentin Matrix Scaffold and Dental Follicle Cells for Dentin Regeneration. Biomaterials 2009, 30, 6708-6723. [CrossRef] [PubMed]

44. Melling, G.E.; Colombo, J.; Avery, S.J.; Ayre, W.; Evans, S.L.; Waddington, R.J.; Sloan, A.J. Liposomal Delivery of Demineralised Dentine Matrix for Dental Tissue Regeneration. Tissue Eng. Part A 2018, 24, 1057-1065. [CrossRef] [PubMed]

45. Nam, J.W.; Kim, M.Y.; Han, S.J. Cranial Bone Regeneration According to Different Particle Sizes and Densities of Demineralized Dentin Matrix in the Rabbit Model. Maxillofac. Plast. Reconstr. Surg. 2016, 38, 27. [CrossRef] [PubMed]

46. Park, M.; Mah, Y.J.; Kim, D.H.; Kim, E.S.; Park, E.J. Demineralized Deciduous Tooth as a Source of Bone Graft Material: Its Biological and Physicochemical Characteristics. Oral Surg. Oral Med. Oral Pathol. Oral Radiol. 2015, 120, 307-314. [CrossRef] [PubMed]

47. Park, S.M.; Kim, D.H.; Pang, E.K. Bone Formation of Demineralized Human Dentin Block Graft with Different Demineralization Time: In Vitro and in Vivo Study. J. Craniomaxillofac. Surg. 2017, 45, $903-912$. [CrossRef] [PubMed]

48. Kim, J.Y.; Kim, K.W.; Um, I.W.; Kim, Y.K.; Lee, J.K. Bone Healing Capacity of Demineralized Dentin Matrix Materials in a Mini-Pig Cranium Defect. J. Korean Dent. Sci. 2012, 5, 21-28. [CrossRef]

49. Lee, D.H.; Yang, K.Y.; Lee, J.K. Porcine Study on the Efficacy of Autogenous Tooth Bone in the Maxillary Sinus. J. Korean Assoc. Oral Maxillofac. Surg. 2013, 39, 120-126. [CrossRef] [PubMed]

50. Salehi, S.; Cooper, P.; Smith, A.; Ferracane, J. Dentin Matrix Components Extracted with Phosphoric Acid Enhance Cell Proliferation and Mineralization. Dent. Mater. 2016, 32, 334-342. [CrossRef] [PubMed]

51. Hefeng, Y.; Yu, H.; Jingjing, S.; Weihua, G.; Weidong, T.; Song, L. Treated Dentin Matrix Enhances Proliferation and Osteogenic Differentiation of Bone Marrow Mesenchymal Stem Cells. West China J. Stomatol. 2016, 34, 281-285.

52. de Oliveira, G.S.; Miziara, M.N.; Silva, E.R.; Ferreira, E.L.; Biulchi, A.P.; Alves, J.B. Enhanced Bone Formation During Healing Process of Tooth Sockets Filled with Demineralized Human Dentine Matrix. Aust. Dent. J. 2013, 58, 326-332. [CrossRef] [PubMed]

53. Pang, K.M.; Um, I.W.; Kim, Y.K.; Woo, J.M.; Kim, S.M.; Lee, J.H. Autogenous Demineralized Dentin Matrix from Extracted Tooth for the Augmentation of Alveolar Bone Defect: A Prospective Randomized Clinical Trial in Comparison with Anorganic Bovine Bone. Clin. Oral Implan. Res. 2017, 28, 809-815. [CrossRef] [PubMed]

54. Lee, C.P.; Colombo, J.S.; Ayre, W.N.; Sloan, A.J.; Waddington, R.J. Elucidating the Cellular Actions of Demineralised Dentine Matrix Extract on a Clonal Dental Pulp Stem Cell Population in Orchestrating Dental Tissue Repair. J. Tissue Eng. 2015, 6. [CrossRef] [PubMed]

55. Qin, W.; Gao, X.; Ma, T.; Weir, M.D.; Zou, J.; Song, B.; Lin, Z.; Schneider, A.; Xu, H.H.K. Metformin Enhances the Differentiation of Dental Pulp Cells into Odontoblasts by Activating Ampk Signaling. J. Endod. 2018, 44, 576-584. [CrossRef] [PubMed]

56. Widbiller, M.; Driesen, R.B.; Eidt, A.; Lambrichts, I.; Hiller, K.A.; Buchalla, W.; Schmalz, G.; Galler, K.M. Cell Homing for Pulp Tissue Engineering with Endogenous Dentin Matrix Proteins. J. Endod. 2018, 44, $956-962$. [CrossRef] [PubMed]

57. Kang, K.J.; Lee, M.S.; Moon, C.W.; Lee, J.H.; Yang, H.S.; Jang, Y.J. In Vitro and in Vivo Dentinogenic Efficacy of Human Dental Pulp-Derived Cells Induced by Demineralized Dentin Matrix and Ha-Tcp. Stem Cells Int. 2017, 2017, 2416254. [CrossRef] [PubMed]

58. Jiao, L.; Xie, L.; Yang, B.; Yu, M.; Jiang, Z.; Feng, L.; Guo, W.; Tian, W. Cryopreserved Dentin Matrix as a Scaffold Material for Dentin-Pulp Tissue Regeneration. Biomaterials 2014, 35, 4929-4939. [CrossRef] [PubMed]

59. Mehrvarzfar, P.; Abbott, P.V.; Akhavan, H.; Savadkouhi, S.T. Modified Revascularization in Human Teeth Using an Intracanal Formation of Treated Dentin Matrix: A Report of Two Cases. J. Int. Soc. Prev. Community Dent. 2017, 7, 218-221. [PubMed] 
60. Vo, T.N.; Kasper, F.K.; Mikos, A.G. Strategies for Controlled Delivery of Growth Factors and Cells for Bone Regeneration. Adv. Drug Deliv. Rev. 2012, 64, 1292-1309. [CrossRef] [PubMed]

61. Um, I.W. Demineralized Dentin Matrix (Ddm) as a Carrier for Recombinant Human Bone Morphogenetic Proteins (Rhbmp-2). Adv. Exp. Med. Biol. 2018, 1077, 487-499. [PubMed]

62. Murata, M.; Sato, D.; Hino, J.; Akazawa, T.; Tazaki, J.; Ito, K.; Arisue, M. Acid-Insoluble Human Dentin as Carrier Material for Recombinant Human Bmp-2. J. Biomed. Mater. Res. A 2012, 100, 571-577. [CrossRef] [PubMed]

63. Kim, S.Y.; Kim, Y.K.; Park, Y.H.; Park, J.C.; Ku, J.K.; Um, I.W.; Kim, J.Y. Evaluation of the Healing Potential of Demineralized Dentin Matrix Fixed with Recombinant Human Bone Morphogenetic Protein-2 in Bone Grafts. Materials (Basel) 2017, 10, 1049. [CrossRef] [PubMed]

64. Um, I.-W.; Kim, Y.-K.; Park, J.-C.; Lee, J.-H. Clinical Application of Autogenous Demineralized Dentin Matrix Loaded with Recombinant Human Bone Morphogenetic-2 for Socket Preservation: A Case Series. Clin. Implant Dent. Relat. Res. 2018. [CrossRef] [PubMed]

65. Um, I.W.; Hwang, S.H.; Kim, Y.K.; Kim, M.Y.; Jun, S.H.; Ryu, J.J.; Jang, H.S. Demineralized Dentin Matrix Combined with Recombinant Human Bone Morphogenetic Protein-2 in Rabbit Calvarial Defects. J. Korean Assoc. Oral Maxillofac. Surg. 2016, 42, 90-98. [CrossRef] [PubMed]

66. Jung, G.-U.; Jeon, T.-H.; Kang, M.-H.; Um, I.-W.; Song, I.-S.; Ryu, J.-J.; Jun, S.-H. Volumetric, Radiographic, and Histologic Analyses of Demineralized Dentin Matrix Combined with Recombinant Human Bone Morphogenetic Protein-2 for Ridge Preservation: A Prospective Randomized Controlled Trial in Comparison with Xenograft. Appl. Sci. 2018, 8, 1288. [CrossRef]

67. Bakopoulou, A.; Papachristou, E.; Bousnaki, M.; Hadjichristou, C.; Kontonasaki, E.; Theocharidou, A.; Papadopoulou, L.; Kantiranis, N.; Zachariadis, G.; Leyhausen, G.; et al. Human Treated Dentin Matrices Combined with Zn-Doped, Mg-Based Bioceramic Scaffolds and Human Dental Pulp Stem Cells Towards Targeted Dentin Regeneration. Dent. Mater. 2016, 32, e159-e175. [CrossRef] [PubMed]

68. Ji, B.; Sheng, L.; Chen, G.; Guo, S.; Xie, L.; Yang, B.; Guo, W.; Tian, W. The Combination Use of Platelet-Rich Fibrin and Treated Dentin Matrix for Tooth Root Regeneration by Cell Homing. Tissue Eng. Part A 2015, 21, 26-34. [CrossRef] [PubMed]

69. Chen, G.; Chen, J.; Yang, B.; Li, L.; Luo, X.; Zhang, X.; Feng, L.; Jiang, Z.; Yu, M.; Guo, W.; et al. Combination of Aligned Plga/Gelatin Electrospun Sheets, Native Dental Pulp Extracellular Matrix and Treated Dentin Matrix as Substrates for Tooth Root Regeneration. Biomaterials 2015, 52, 56-70. [CrossRef] [PubMed]

70. Athirasala, A.; Tahayeri, A.; Thrivikraman, G.; Franca, C.M.; Monteiro, N.; Tran, V.; Ferracane, J.; Bertassoni, L.E. A Dentin-Derived Hydrogel Bioink for 3d Bioprinting of Cell Laden Scaffolds for Regenerative Dentistry. Biofabrication 2018, 10, 024101. [CrossRef] [PubMed] 